\title{
Developing an Assessment Tool of ITIL Implementation in Small Scale Environments
}

\author{
Abir EL YAMAMI, Souad AHRIZ, Khalifa MANSOURI, Mohammed QBADOU, Elhossein ILLOUSSAMEN \\ Laboratory: Signals, Distributed Systems and Artificial Intelligence (SSDIA) \\ ENSET Mohammedia, Hassan II University of Casablanca, Morocco
}

\begin{abstract}
Considering the problematic of IT Service Management (ITSM) frameworks Implementation in SMEs, among the various frameworks available for companies to manage their IT services, ITIL is recognized as the most structured and effective framework. Nevertheless, ITIL has been criticized for not been appropriate for small scale enterprises. This paper provided a practical tool formally developed according to Design Science Research (DSR) approach, it aimed to find out the key factors that affect ITIL implementation success in SMEs, the objective was to eliminate the misunderstanding of the IT service management model's implementation purpose. It determines various Critical Success Factors (CSFs) of ITIL implementation, the weight of each CSF is calculated with Analytical Hierarchy Process (AHP) and the evaluation was executed in a Moroccan SME. Therefore, it provides an evaluation method in order to help researchers and managers to determine the issues related to local culture of SMEs while adopting ITIL Framework. Results show that the top management support is the most important factor for Moroccan SMEs. It is found that an approach for determining ITIL processes implementation sequencing order need to be developed in order to achieve quick wins.
\end{abstract}

Keywords-Component; IT Service Management (ITSM); Information Technology Infrastructure Library (ITIL); CSFs (Critical Success Factors); Design Science Research (DSR); Analytical Hierarchy Process (AHP); Small and Medium-sized enterprises (SMEs)

\section{INTRODUCTION}

The issue of IT service management occupies central paramount position among the preoccupations of the organizations' decision makers, it affects all types of organizations. Economists underline the essential role that SMEs play in enhancing growth and creating employment especially in underdeveloped countries where SMEs play a critical role. In fact, SMEs have some specific characteristics that have to be considered separately, without interacting them with those of large size enterprises.

SMEs have a simple structure that essentially is based on a limited group of individuals, customers are not satisfied due to the bad management of IT services. They are submerged by incidents and users' problems and do not always have the capabilities to contribute effectively to the creation of the value within companies [1]. Therefore, SMEs sought to implement frameworks of good practices to facilitate the description and the implementation of IT services. ITIL framework is positioned on the management of IT-services, according to a study of CIGREF [2] ITIL is the most used by organizations.

According to International Data Corporation (IDC), Morocco is at the top of the Maghreb countries, it represents more than $40 \%$ of total IT spending in the area, moreover Moroccan SMEs invest more in IT [3], hence the need for improving the quality of IT services.

Moroccan SMEs are characterized by the centralization and the customization of the management around the ownermanager, The owner directs, manages and participates in the production. What is translated by a lack of separation of ownership and control, and the main managerial functions are frequently concentrated in the hands of the manager/owner or his family [4].

As matter of fact, several elements which have a remarkable impact on affecting the implementation of ITSM framework must be taken into account. IT Practitioners appear to be more process oriented. They identify a set of practices that should be followed, however, none of ITSM practitioner make reference to any of the critical success factors, not even to the success factors concept as a whole.

Determining the right critical success factors of ITIL implementation remain a complex endeavour. Thereby, researchers study and perceive the critical success factors for adopting ITIL practices.

Summarizing, ITSM frameworks are hard to implement especially in SMEs. There are several misunderstandings in ITSM critical success factors that must be clarified in order to promote a correct implementation and use of ITSM practices.

We propose to perform an exploratory research by analysing several ITIL CSFs case studies in order to obtain possible ITIL critical factors that aiming to assist SMEs and practitioners by providing more guidance on how ITIL components can be implemented. The aim of this paper is to help the decision makers in Moroccan SMEs to better identify ITIL implementation success factors using a systematic approach, at the same time, the use of formal design and an evaluation process which assure the pertinence of the solution.

In the flow of this paper, first the followed research methodology is presented in Section II, then a literature review about ITSM, ITIL and CSFs identified from literature is presented in Section III, followed by the presentation of our proposal in Section IV. Finally, the evaluation techniques of our proposal are presented in the next section (Section V) to sum up with a conclusion. 


\section{RESEARCH METHODOLOGY}

In this paper the research methodology used is Design Science Research (DSR).

In his publication, Herbert Simon articulated the difference between natural science and design science; the first is concerned with how things are while the second is concerned with how things ought to be [5].

DSR approach can be defined as a system of principles, practices and procedures to carry out a study [6]. Information system studies can draw advantage from this methodology by using theories from diverse disciplines: computer science, engineering, social science, economics and philosophy to address problems at the intersection of IT and organizations [7]. Therefore, the DSR paradigm is proactive with respect to technology. It focuses on creating and evaluating innovative IT artefacts that enable organizations to address important information-related tasks [8].

Authors of [7] present a recent development of the initial design science framework. The framework decouples the goals of DSR methodology into three research cycles as shown in Fig. 1.

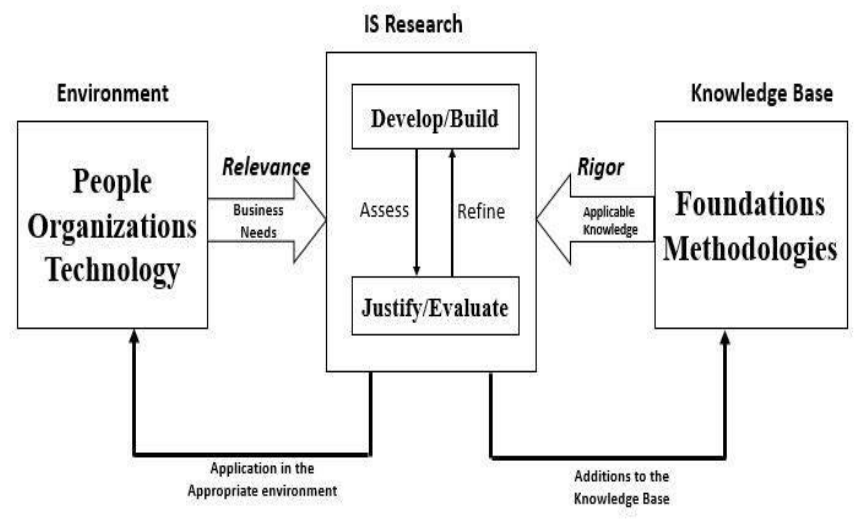

Fig. 1. DSR cycles as presented by [7].

The relevance is achieved through the identification of business needs and field testing of an artefact within an environment.

Rigor is attained by grounding the research in existing foundation and methodologies.

Design is achieved through a design cycle in which the artefact is built and evaluated through the relevance and rigor cycles [9].

DSR provides four design artefacts (constructs, models, methods and instantiation). In this paper we will focus on constructs and models. The constructs allow describing a problem domain aspects terminology [10], while models use constraints to represent a real world situation, the design problem and the solution space [5].

The constructs that we propose is the domain definition and ITIL implementation CSFs in Section III.
The model of this paper is defined through the integration of different CSFs, it is represented in Section IV.

In the evaluation stage, we used a case of study, interviews with practitioners and Osterle Principles in order to evaluate our proposal.

\section{LITERATURE REVIEW}

This section elucidates ITSM concept, ITIL framework and then presents the findings from the most significant empirical research in ITIL CSFs.

\section{A. ITSM (IT Service Management)}

ITSM is an approach for managing information systems, it represents the information system as a set of capabilities that bring value to customers in the form of services. It can be defined as a set of processes that cooperate to ensure the quality of IT services according to the levels of services agreed by the customers [11]. Authors of [12] precise that ITSM can be seen as a market-oriented philosophy, which involves a customer-supplier relationship instead of a relationship as project partners. ITSM approach focuses not only on the technical aspects of computing but also on the alignment of the services and functions provided by IT department. It focuses also on the lifecycle of IT services from design to continuous improvement. According to [13], ITSM focuses on defining, managing and delivering IT services to support business objectives and customer needs through IT operations.

Based on a study of CIGREF [14], ITIL is the most ITSM framework used by organizations. The success of this framework has allowed it to become an international standard: ISO 20000. The themes of ISO 20000 correspond to the fields of application of ITIL, but for each theme, ITIL covers more requirements than ISO 20000 standard. Thus, the ISO 20000 standard can be considered as a first step in the adoption of ITIL components.

\section{B. ITIL (IT Service Infrastructure Library)}

ITIL is a collection of best practices for managing IT, collected from sources all over the world. It was developed in the UK in the $1980 \mathrm{~s}$ by the government to improve its management of IT. ITIL allows establishing a suite of individually owned processes that impose a balanced and comprehensive structure on all IT endeavors. It is neither a process nor a method, nor a tool [15], it's a library of books listing the best practices for improving the quality of IT and user support by creating the service desk function that centralizes and manages all information management systems. ITIL covers a wide field of IT governance by focusing on the concept of service and quality. It uses the concept of service contract between service requesters and service providers.

ITIL comprises three primary segments: service support and service delivery, it defines key processes that organizations must put in place to provide IT services with a high quality for its users, and third area which consists on ITIL processes such as security management and application management.

The current version is ITIL v3, updated in 2011 and organized into five books: Service Strategy [16], Service 
Design [17], Service Transition [18], Service Operation [19] and Continual Service Improvement [20].

ITIL life cycle consists of five phases, each phase includes processes, functions, roles and performance measures:

- Service Strategy: Covers the strategic vision, design, development and implementation of service management. It is composed of three processes (portfolio management, demand management, financial management).

- Service Design: Covers architecture, processes, policies and documentation and consists of seven processes (Catalogue Design, Service Level Management, Supplier Management, Availability Management, Continuity Management, Capacity and Information Security Management).

- Service Transition: Covers the elements needed to start production of services (construction, testing, documentation and training) and consists of seven processes (Configuration Management, Change Management, Release Management, Knowledge Management, Transition planning and support, service validation and testing and evaluation of execution of requests).

- Service Operation: Covers the elements necessary for the provision of services, it guides the execution of processes necessary for the management of services and technologies. It consists of five processes (event management, incident management, problem management, request management and access management) and four functions (service desk, technical management, application management and IT operations management).

- Continual Service Improvement: Covers service improvement processes, service measurement and service reporting.

Concerning small structures, two approaches for ITIL processes implementation have been presented. The first one is "small-scale" [21] which attempts to adjust ITIL and to make it accessible to SMEs by simplifying the service life cycles. This method proposes to group processes and to make an hybrid process in order to optimize the competences and to increase the performance of individuals, the second philosophy is "Lite" of Malcom Fry [22], which consists on implementing ITIL processes that would result in a quick result for the SME either as a starting point for full implementation or as a deliverable for those who do not wish to fully implement ITIL.

\section{Analysis of ITIL CSFs}

ITIL implementation confronts several challenges. The documentation provides only general guidance on the implementation of ITIL. Managers doubt the best practices to adopt ITIL and rely on consultants and suppliers. The success of ITIL is difficult to measure, because there is no established evaluation standard [23]. Furthermore, there are no tangible results that we can measure. In order to overcome these limitations, researchers are studying and perceiving the critical success factors of ITIL implementation, which companies should take into consideration when adopting ITIL good practices.

CSFs can be defined as the key areas that allows achieving a high level of ITIL implementation success. Researchers have extensively discussed these factors in literature. In fact, two approaches have been used to identify CSFs: Case studies that asked for the important factors for success implementation of ITIL and surveys that asked respondents to rank the relevance of predefined alternatives.

A systematic approach to successful implementation of ITIL is proposed in [23] and applied it to a case study of a company in United Arab Emirates, in [24], author investigated to what effect service oriented IT management in European companies by conducting six case studies and identifies six success factors of pertinent reorganization of IT management, In [25], authors reported a single case study of large public sector organization in Australia, an exploratory research reports on four case studies of successful implementation of ITSM using ITIL v2 framework is made in [26], stakeholders in organizations implementing ITIL processes about CSFs are interviewed in [27], [28], a list of concise CSFs, and nontechnical best practices for ITIL implementation based on his experience about ITIL is provided in [29], and finally a metaanalysis of previous studies on critical success factors is proposed in [30].

From the literature review, we identified seven key critical success factor and we explained their significance trough Table 1. Then, we summarized the conducted comparison between nine research papers in terms of reported CSFs in Table 2.

TABLE I. IDENTIFIED CSF OF ITIL IMPLEMENTATION

\begin{tabular}{|l|l|}
\hline Key CSF & Significance \\
\hline Top management support & $\begin{array}{l}\text { Organizations considering ITIL implementation } \\
\text { should link this initiative with the corporate } \\
\text { strategy, endorse policy and enforce compliance } \\
\text { before proceeding, top management must } \\
\text { guarantees the need resources for consultancy, } \\
\text { tools and training. }\end{array}$ \\
\hline $\begin{array}{l}\text { Training /personal } \\
\text { development }\end{array}$ & $\begin{array}{l}\text { Training and staff awareness of ITIL } \\
\text { Knowledge of ITIL documentation }\end{array}$ \\
\hline Applied Technologies & $\begin{array}{l}\text { Selecting tools and technologies that allow } \\
\text { easier configuration of processes }\end{array}$ \\
\hline $\begin{array}{l}\text { Communication and } \\
\text { collaboration }\end{array}$ & Effective communication among stakeholders \\
\hline Change management & Reduce employees resistance \\
\hline Process priority & $\begin{array}{l}\text { Focusing on processes before selecting tools and } \\
\text { technologies, tools should be selected to support } \\
\text { and integrate processes }\end{array}$ \\
\hline Quick wins & $\begin{array}{l}\text { Selecting processes that promote quick wins to } \\
\text { the organization }\end{array}$ \\
\hline
\end{tabular}


TABLE II. CLASSIFICATION OF IDENTIFIED CSFS FROM LITERATURE

\begin{tabular}{|c|c|c|c|c|c|c|c|c|c|c|}
\hline Key CSF & {$[24]$} & {$[25]$} & [26] & [27] & [28] & [29] & [34] & {$[30]$} & {$[35]$} & SUM \\
\hline Top management support & - & $\bullet$ & • & $\bullet$ & & & $\bullet$ & $\bullet$ & • & 7 \\
\hline Training /personal development & $\bullet$ & $\bullet$ & $\bullet$ & $\bullet$ & $\bullet$ & $\bullet$ & $\bullet$ & $\bullet$ & $\bullet$ & 9 \\
\hline Applied Technologies & & $\bullet$ & $\bullet$ & & & & $\bullet$ & - & $\bullet$ & 5 \\
\hline Communication \& collaboration & & & - & $\bullet$ & & & $\bullet$ & $\bullet$ & $\bullet$ & 5 \\
\hline Change management & & & & & & & $\bullet$ & $\bullet$ & $\bullet$ & 3 \\
\hline Process priority & & & $\bullet$ & & & & $\bullet$ & & $\bullet$ & 3 \\
\hline Quick wins & & $\bullet$ & & & & & & & & 1 \\
\hline SUM & 2 & 4 & 5 & 3 & 1 & 1 & 6 & 5 & 6 & \\
\hline
\end{tabular}

IV. PROPOSAL

\section{A. Analytical Hierarchy Process (AHP)}

The AHP method was developed in the 1980s by Saaty [31], it is a systematic decision making method which includes both qualitative and quantitative techniques. It is useful for obtaining a single assessment value based on different indicators or criteria. It simplifies the process of decision making by subdividing a complex problem into a series of structured steps where each element in the hierarchy of criteria is supposed to be independent of all the others. The analytic network process is used when there is interdependence among criteria.

The relative importance of decision criteria in AHP is assessed trough a pairwise comparisons, to establish a priority value $a_{i j}$ for each criteria, decision maker examines two alternatives by considering one criteria and indicates a preference. The standard numeric scale used for AHP is 1-9 scale which lies between "equal importance" to" extreme importance", the value 9 indicates that one factor is extremely less important than the other, while value 1 indicates equal importance. At each level of the criteria hierarchy we obtain an $n * n$ square matrix, where $n$ is the number of elements of the level.

We choose AHP because it is ideal for complex multicriteria decision making problems where both qualitative and quantitative aspect of a problem can be incorporated. Furthermore, it allows incorporating subjective opinions from different stakeholders on the critical factors that affect ITIL implementation.

AHP allows building consensus among decision makers, each member can compare their judgments to those of the other members and it gives them better understanding of the impact of their priorities.

AHP decompose the decision into the following steps [32]:

1) Define the problem.

2) Model the problem as a hierarchy from the top with the goal of the decision, then the objectives from a board perspective through intermediate levels.

3) Evaluate the hierarchy by constructing a set of pairwise comparison matrices.
4) Establish priorities by using the priorities obtained from the comparisons to weight the priorities in the level immediately below, then for each element in the level below add its weighted values and obtain its overall priority.

\section{B. Artifact Design}

Since the decision criteria in this research are qualitative, prioritization of ITIL implementation CSFs is considered as a complex model of multi-criteria decision making.

Understanding the reasons behind ITIL implementation success or fail requires analysing the type of problematic by companies' actors and their self-reflective judgement concerning the significance of ITIL implementation CSFs. Employees make their own judgement and act in a way that strengthen or weaken the rationalization of IT department resources. Our work seeks to provide a multi criteria approach to find out the reasons behind ITIL implementation success/ Fail in Moroccan SMEs.

In order to achieve the main objective of our established hierarchy which is the successful implementation of ITIL, 7 CSFs are hierarchically organized in three levels (Managerial, Technical and behavioural) as shown in Fig. 2

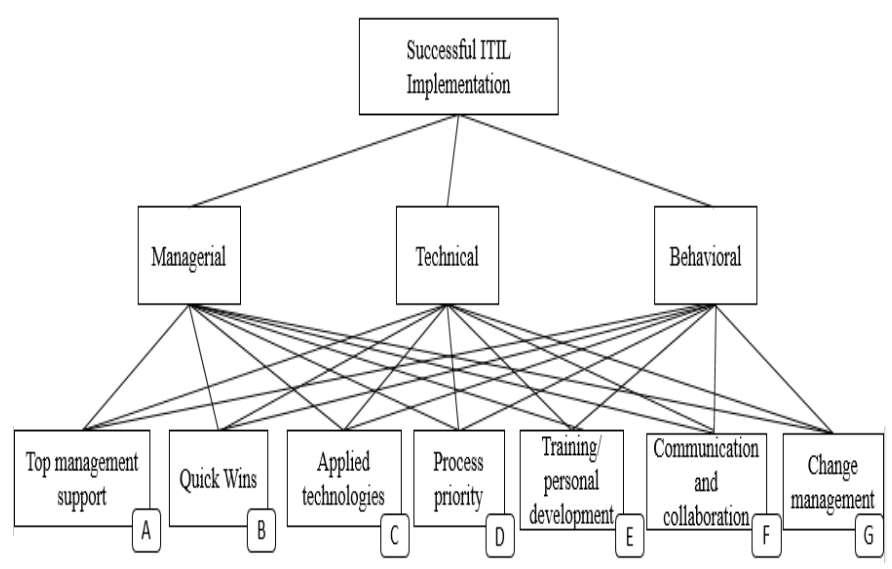

Fig. 2. AHP hierarchy. 
In the following section, we analytically describe the various aspects of the implementation of this model in a Moroccan SME.

\section{EVALUATION}

\section{A. Case of Study}

For the evaluation of our model, a case study is executed. For that aim, we selected a Moroccan SME that operates in the field of information technology. This SME provides services to external customers for over 20 years. The team is composed of 23 people, 12 of whom are responsible for the provision of IT services. The main source of the company's revenue depends primarily on IT services delivering.

In order to test our hierarchy presented in Fig. 2, we interviewed the main actors involved in adopting ITIL good practices in our SME of reference; we chose the participants based on their job and their involvement in ITIL implementation, and we covered different categories of users (IT staff, IT users, Managers).

Fig. 3, 4 and 5 present the results of the pairwise comparison of ITIL, CSFs established by ITIL Project implementation stakeholders.

\section{IT STAFF}

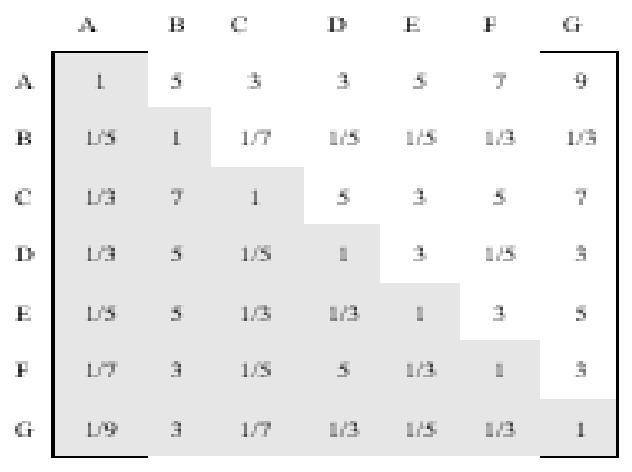

Fig. 3. IT STAFF decision matrix.

\section{MANAGERS}

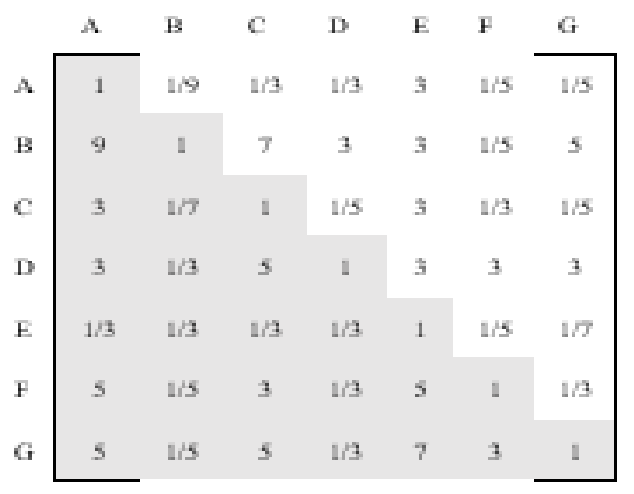

Fig. 4. Managers decision matrix.

\section{IT USERS}

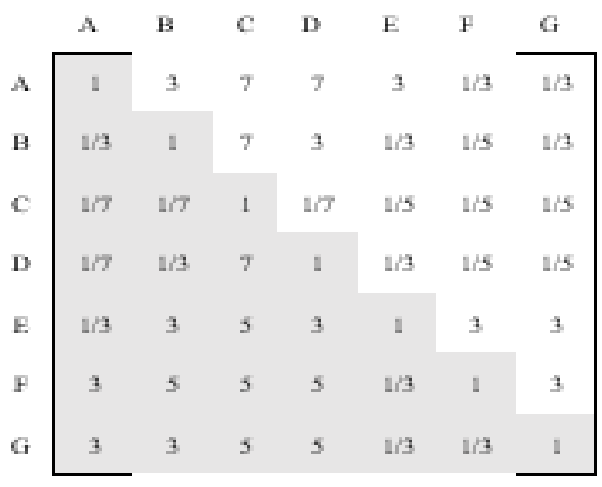

Fig. 5. IT users decision matrix.

We calculate the weights obtained for each ITIL implementation CSF, and for each CSF category according to the different stakeholders.

Table 3 shows the priorities calculated using AHP method and the ranking of the various CSFs selected according to the three actors (IT Staff, Managers, and IT users), Table 4 shows the CSFs classification according to the categories (Managerial, Technical or Behavioural) for the three stakeholders of ITIL processes adoption project while Table 5 presents the final ranking of the different criteria used in our study.

TABLE III. CSFS PRIORITIES

\begin{tabular}{|l|l|l|l|l|}
\hline Factors & IT Staff & Managers & IT Users & Rank \\
\hline Managerial & $44.00 \%$ & $\mathbf{4 3 . 3 0 \%}$ & $27.00 \%$ & 1 \\
\hline Technical & $\mathbf{4 5 . 0 0 \%}$ & $29.50 \%$ & $30.00 \%$ & 2 \\
\hline Behavioral & $11.00 \%$ & $27.20 \%$ & $\mathbf{4 3 . 0 0 \%}$ & 3 \\
\hline
\end{tabular}

TABLE IV. CSFS CLASSIFICATION

\begin{tabular}{|l|l|l|}
\hline Criteria & Weight & Rank \\
\hline Top management support & $\mathbf{2 0 . 7} \%$ & $\mathbf{1}$ \\
\hline Quick Wins & $12.8 \%$ & 6 \\
\hline Applied technologies & $9.3 \%$ & 7 \\
\hline Process priority & $13.0 \%$ & 5 \\
\hline Training/ personal development & $13.0 \%$ & 4 \\
\hline Communication and collaboration & $\mathbf{1 7 . 4 \%}$ & $\mathbf{2}$ \\
\hline Change management & $13.9 \%$ & 3 \\
\hline
\end{tabular}


TABLE V. CSFS PRIORITY CALCULATION

\begin{tabular}{|l|l|l|l|l|l|l|}
\hline \multirow{2}{*}{$\begin{array}{l}\text { USERS } \\
\text { CSF }\end{array}$} & \multicolumn{2}{|l|}{ IT STAFF } & \multicolumn{2}{l|}{ Managers } & \multicolumn{2}{l|}{ IT Users } \\
\cline { 2 - 7 } & Priority & & Priority & & Priority & \\
\hline $\begin{array}{l}\text { Top management } \\
\text { support }\end{array}$ & $\mathbf{4 1 \%}$ & $\mathbf{1}$ & $4.1 \%$ & 6 & $19 \%$ & 3 \\
\hline Quick Wins & $3 \%$ & 7 & $\mathbf{3 9 . 2 \%}$ & $\mathbf{1}$ & $8 \%$ & 5 \\
\hline Applied technologies & $\mathbf{2 4 \%}$ & $\mathbf{2}$ & $5.5 \%$ & 5 & $3 \%$ & 7 \\
\hline Process priority & $10 \%$ & 4 & $\mathbf{2 0 . 2 \%}$ & $\mathbf{2}$ & $5 \%$ & 6 \\
\hline $\begin{array}{l}\text { Training/ personal } \\
\text { development }\end{array}$ & $11 \%$ & 3 & $3.8 \%$ & 7 & $\mathbf{2 2 \%}$ & $\mathbf{2}$ \\
\hline $\begin{array}{l}\text { Communication and } \\
\text { collaboration }\end{array}$ & $8 \%$ & 5 & $10.5 \%$ & 4 & $\mathbf{2 6 \%}$ & $\mathbf{1}$ \\
\hline Change management & $4 \%$ & 6 & $16.7 \%$ & 3 & $17 \%$ & 4 \\
\hline
\end{tabular}

The results show that IT Staff, IT users and Managers have different priorities in terms of ITIL implementation success factors.

IT Staff consider that the top management support and the applied technologies are the most important factors. In the other hand, they consider that the change management and quick wins are the least important CSFs.

The second group is IT users, it considers that communication and cooperation between the different stakeholders is the most important factor, while the applied technologies and process priority definition are the least important.

The third group is the SME Top management; SME managers are looking for quick wins, therefore, ITIL process implementation sequencing order is very important for managers, while user training comes in the last position.

According to Table 4, managerial factors had the first place, followed by technical factors and then behavioural factors. In fact, Top management support takes the first position with $20.7 \%$, which is explained by the nature of the company (SME), in the second place comes communication and collaboration between the different stakeholders with $17.4 \%$, and finally, in the third place come Change management, staff training and process priority with $13.9 \%$, $13.0 \%$ and $13.0 \%$, respectively (Table 5).

While quick wins take first place for managers and the applied technologies take the second place for IT Staff, these factors are positioned in the end of the final ranking with $12.8 \%$ and $9.3 \%$ respectively.

\section{B. Interviews with Practitioners}

In order to validate our model. We used interviews with practitioners' technique to validate our research purpose and its results. For that aim, We selected a Moroccan SME that recognized a high level of resistance by their staff when implementing ITIL processes.

We investigated the main actors involved in ITIL components implementation project about the reasons that hinder its success:

The SME's IT department reports that IT staff have very close personal relationships with IT users, so IT users ignore customer service and tend to send their requests via e-mail without contacting the service Desk. The second reason behind the failure of ITIL implementation project is that the adoption of ITIL components was mismanaged; the SME did not follow any project management methodology, the deliverables were not accurate and finally, this project was not prioritized by the top management.

According to IT users the lack of ITIL skills is the main factor that caused the failure of ITIL implementation project, so communication and change management make success rather than pressure on users. The first step is to create an ITIL culture by educating staff through communication and training.

The SME Manager precises that "we must not pretend that things work when they are not, we must give priority to honest communication between all stakeholders. In order to keep everyone involved, it is important to have tangible results. IT department has to support and encourage the movement, to motivate people to use these tools and integrate them in the company's information system".

We note a desynchronized visions between the business and IT Staff about critical success factors of ITIL implementation, IT department expects more involvement form IT users, while the latter expects more involvement of IT department in their business. Each stakeholder has particular expectations regarding the implementation of ITIL processes and neglects its role in contributing to the successful implementation of these processes. Hence the need for a systemic method allowing organizations to involve all staff in the implementation of ITIL project in order to avoid resistance to change. Finally, we have exposed our model to the practitioners and it has been validated.

\section{Osterle Principles}

In order to distinguish scientific research from the solutions developed in the practitioners' community, Osterle [33] precises that scientific research need to be characterized by abstraction, originality, justification and benefit.

- Abstraction: This paper proposes a multi criteria approach to evaluate success factors of ITIL implementation for specific industries and regions.

- Originality: The artefact proposed is not present in the Body of Knowledge of the domain.

- Justification: The various methods proposed to evaluate the artefact should justify the artefact.

- Benefit: The critical success factors of ITIL framework elicitation will help SMEs to better implement ITIL components, achieving in that way a better alignment between the business and the IT.

\section{DISCUSSION}

Given the critical consequences that IT can have on the survival of SMEs in a competitive environment, ITSM practices have becoming a necessity for SMEs that must be investigated. ITIL is recognized as the framework the most used by companies in the world. Nevertheless this framework proposes only general indications of the implementation of the 
proposed components. Furthermore, ITIL is criticized as being appropriate for large enterprises and less for SMEs.

SMEs, venturing into re-engineering process services, can fall into the trap of the complexity of such projects. Indeed, we wish, through this work, to contribute to the literature interested in adopting ITIL practices by providing a practical tool formally developed according to Design Science Research approach, it aims to find out the key factors that affect ITIL implementation success in SMEs. The main objective is to eliminate the misunderstanding of IT service management model's implementation purpose. It addresses an area of relevance to both practitioners and academics and suggests solutions that can help managers to personalize IT services practices to suit the characteristics of small scale enterprises.

In this context, the design was fulfilled by producing two artefacts: A construct and a model. In the construct, we elucidated the ITSM frameworks implementation CSFs. The constructed model consists of a set of 9 CSFs, it provides a multi-criteria approach to find out the type of problematic encountered by SMEs' actors and the significance of each ITSM CSF.

The results show that there is a desynchronized vision between top management, business and IT actors in terms of their self-reflective judgement concerning the priorities of ITIL implementation CSFs.

According to the SME of reference: the managerial factors take the first priority, the top management support is the first key for the successful implementation of ITIL. In fact, SMEs managers are seeking for quick wins: thus it calls for revisiting this framework while taking into consideration the problematic of ITIL processes sequencing in order to put in place ITIL processes that would give a quick result to SMEs.

Tailoring ITIL framework problem is a strategic problem that involves a myriad of organizational and technical issues. So to what extent can SMEs adopt IT services Management practices to manage those processes? SMEs need less bureaucratic more people focused forms of ITSM approaches than traditionally used by larger organizations. ITSM theoreticians need to recognize that different versions of ITIL are required in different circumstances. The results of our model should aid in the development of ITIL implementation roadmaps for use by the non-specialist ITIL in SMEs.

\section{CONCLUSION}

Recently, ITSM have become a necessity for SMEs that must be investigated; ITIL framework is the most used framework within organizations. Nevertheless, ITIL is essentially designed for large enterprises, the adoption of this framework by SMEs is often a source of confusion.

Responding to those needs and enabling SMEs to implement ITIL processes, we proposed a multi criteria approach to evaluate success factors of ITIL implementation project which allows the understanding of critical factors that hinder or facilitate ITIL adoption in SMEs.

The research methodology adopted in this paper was design science research. To validate our research we used interviews with practitioners' technique, Osterle principles, and a case study. This latter was performed in a Moroccan SME, the results was investigated and the difficulties encountered by the SME was highlighted.

ITIL framework is based largely on research conducted in the USA, UK and other developed countries, this framework do not describe adequately how ITSM is carried out in developing countries. For a successful implementation of ITIL in Moroccan SMEs, this framework should be revised taking into consideration the specific realities of Moroccan SMEs. Future works will be focused on the proposal of a new approach for the adoption of ITIL best practices by Moroccan SMEs.

\section{REFERENCES}

[1] K. M. M. Q. E. I. Abir EL YAMAMI, "Toward a new multi-agents architecture for the adoption of ITIL framework by small and mediumsized enterprises," in 4th IEEE International Colloquium on Information Science and Technology (CiSt), Tangier, 2016.

[2] CIGREF, "Referentiels_de_la_DSI_CIGREF_2009.pdf," 2009. [Online].Available:

http://www.cigref.fr/cigref_publications/RapportsContainer/Parus2009/R eferentiels_de_la_DSI_CIGREF_2009.pdf. [Accessed 0104 2016].

[3] I. D. Corporation, "Les prévisions d'IDC pour le Maroc," 2013.

[4] M. DABDOUB, "Quelles roles des acteurs locaux pour le développement des PME Marocaines?" Mostapha DABDOUB, 2013.

[5] H. Simon, "The Science of the Artificial," MIT Press, 19.

[6] R. S. D. Almeida, "Implementing IT Governance Information Systems," 2013.

[7] A. M. S. P. J. a. R. S. Hevner, "Design Science in Information Systems Research," MIS Quarterly, vol. 28, pp. 75-105, 2004.

[8] B. T. Ajantha Dahanayake, "Enriching Conceptual Modelling Practices through Design Science," in Lecture Notes in Business Information Processing , 2011.

[9] A. R. Hevner. 19(2), "The three cycle view of design science," Scandinavian J. Inf. Systems, vol. 19, 2007.

[10] M. B. T. a. K. H. Schermann, "Explicating Design Theories with Conceptual Models: Towards a Theoretical Role of Reference Models", 2009.

[11] Young, "An introduction to IT service management," 2004.

[12] H. A. B. W. Zarnekow R, "Service-orientiertes IT-management: ITILBest-Practices und Fallstudien," Springer, 2005.

[13] W. M. E.-H. L. Conger S, "Service management in operations," in 14th Americas conference on information systems, Canada, 2008.

[14] CIGREF, "Gouvernance du Système d'Information," 2011.

[15] C. NAWROCKI, INTRODUCTION à ITIL - Service delivery, Service Support, itPMS, 2005.

[16] C. Office, ITIL service strategy, Norwich: the Stationery Office (TSO), 2011.

[17] C. Office, ITIL Service Design, Norwich: the Stationery Office (TSO), 2011.

[18] C. Office, ITIL Service Transition, Norwich: the Stationery Office (TSO), 2011.

[19] C. Office, ITIL service Operation, Norwich: the Stationery Office (TSO), 2011.

[20] C. Office, ITIL Continual service improvement, Norwich: the Stationery Office (TSO), 2011.

[21] S. Taylos, ITIL V3 Small-scale Implementation, United Kingdom: TSO, 2009.

[22] F. Malcom, A road map to full or partial ITIL implementation, London: TSO, 2010.

[23] Z. M. Norita Ahmad, "Systematic Approach to successful Implementation of ITIL," Procedia Copmuter Science, pp. 237-244, 2013. 
[24] G. T. B. Axel Hochstein, "Service Oriented IT Management: Benefit, Cost and Success F actors," in European Conference on Information Systems, 2005.

[25] C.-s. T. a. s. Tan, "Implementing centralised IT Service Management: Drawing Lessons from the Public Sector," in Australasian Conference on Information systems, 2007.

[26] C. \&. C.-S. A. Pollard, "Justifications, Strategies, and Critical Success Factors in Successful ITIL Implementations in U.S. and Australian Companies: An Exploratory Study," Information Systems Management, 2009.

[27] J. Iden, "Setting the stage for a successful ITIL Adoption; A delphi study of IT experts in the Norwegian armed forces," Information systems management, 2010.
[28] J. Kabachinski, "Have You Heard of ITIL? It's Time You Did," Biomedical Instrumentation \& Technology, 2011.

[29] H. Marquis, "ITIL: what is and what is not," Business communication review, 2006.

[30] N. H. \&. H. M. Sarvenaz Mehravani, "ITIL adoption model based on TAM," IACSIT Press, 2011.

[31] T. Saaty, "The analytical hierarchy process", New York: Mc Graw Hill, 1980.

[32] T. L. Saaty, "Decision making with the analytic hierarchy process," Services Sciences, p. 84, 2008.

[33] H. B. J. F. U. H. T. K. D. K. H. L. P. M. P. O. A. a. S. E. Osterle, "Memorandum on Design-Oriented Information Systems Research", European Journal of Information Systems, EJIS, pp. 7-10, 2011. 